\title{
ÁREAS METROPOLITANAS DE BELÉM E BRASÍLIA Novos recortes para análise
}

\author{
Ricardo Batista Bitencourt \\ Universidade de Brasília e Universidade Paulista \\ Doutorando orientado por Romulo José da Costa Ribeiro \\ ricardobbitencourt@gmail.com \\ Ramon Fortunato Gomes \\ Universidade de Brasília \\ Doutorando orientado por Romulo José da Costa Ribeiro \\ EMail: ramon.fortunato.gomes@gmail.com
}

\section{RESUMO}

No cenário globalizado das cidades contemporâneas, das trinta e cinco áreas metropolitanas brasileiras, grande parte definidas sob a égide da Constituição Federal de 1988, emergem dois tipos de metrópoles: as funcionais e as formais, cujos arranjos institucionais, incipientes e oportunos, dificultam a gestão de uma realidade em desenvolvimento. Entre elas, a Região Integrada de Desenvolvimento do Distrito Federal (RIDE DF) e a Região Metropolitana de Belém (RM Belém).

O pressuposto de que o conhecimento dos reais perímetros (metrópole funcional), para além daqueles definidos em lei (metrópole formal), contribui para a melhoria da aplicação de recursos e para o desenvolvimento urbano brasileiro, guia este artigo, interligado a um trabalho investigativo maior concentrado na morfologia urbana, visando identificar, por meio de critérios (população, densidade, dispersão, crescimento populacional, distâncias e tempos de viagem) seus perímetros metropolitanos funcionais.

Palavras chave Brasil, metropolização, dispersão, densidade.

\begin{abstract}
In the globalized scenario of contemporary cities, there is two types of metropolis in Brazil, defined under principles of the Federal Constitution of 1988: functionals and formals, whose incipient and timely institutional arrangements make the management of a developing reality. Among them, the Integrated Development Region of the Federal District (RIDE DF) and the Metropolitan Region of Belém (RM Belém). The assumption that the knowledge of the real perimeters (functional metropolis), besides those that the law defines (formal metropolis), contributes to the improvement of the application of resources and to Brazilian urban development, guides this articlethe, linked to a larger research work concentrated in the urban morphology, aiming to identify, through criteria (population, density, dispersion, population growth, distances and travel times) the functional metropolitan perimeters of the two featured metropolis.
\end{abstract}

Key words: Brazil, metropolization, dispersion, density. 


\section{AS METRÓPOLES BRASILEIRAS}

Segundo Castells (2000), metrópole é o espaço de características urbanas que se distingue das precedentes não só pelo tamanho, mas pela difusão nesse espaço das atividades, das funções e dos grupos interdependentes, aplicada uma dinâmica social independente das ligações geográficas. Trata-se de uma estrutura urbana capaz de irradiar as definições e os preceitos da sociedade, a qual, como descreve Santos (1990), funciona e evolui segundo parâmetros globais, mas com especificidades locais. Tais especificidades são condições estabelecidas entre os núcleos periféricos e o núcleo central, que impactam a localização de moradia, o emprego, as atividades de consumo, motivando a circulação cotidiana entre as duas porções do território. No entanto há registros atualizados que destacam outras formas contemporâneos de organização, que também complexificam o território, a saber.

O quadro metropolitano brasileiro conta " (...) atualmente com trinta e cinco regiões metropolitanas - RMs e três regiões integradas de desenvolvimento econômico - RIDEs" (Garson; Ribeiro \& Rodrigues, 2010: 2) (Figura 1). Nesse quadro, segundo Castello Branco et al (2013:117): “(...) tem-se um conjunto de RMs extremamente heterogêneas" cujo "caráter metropolitano atribuído a algumas (...) chega a ser questionável (...)". Sendo possível verificar-se a existência de dois tipos de metrópoles: as funcionais e as formais.

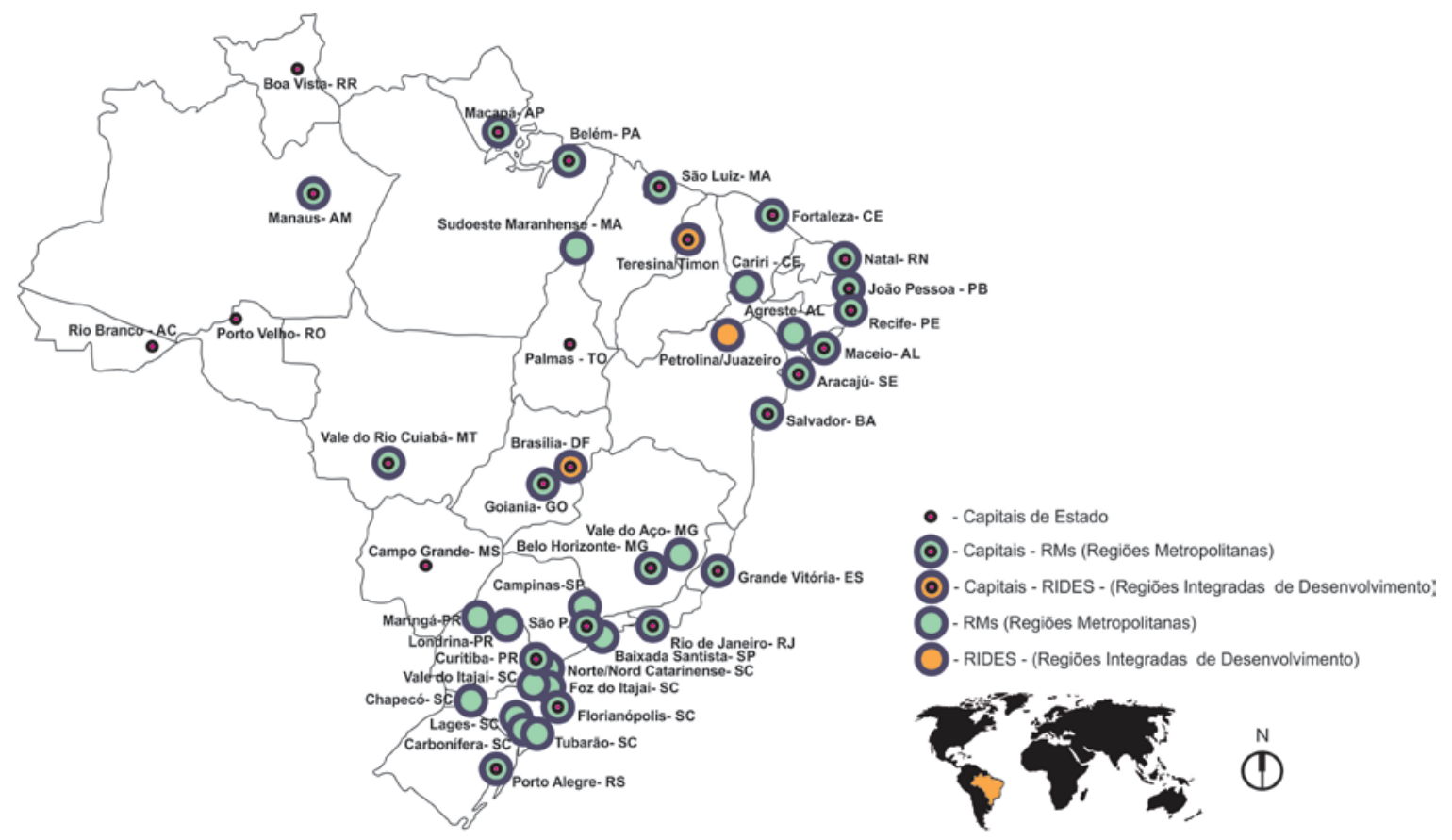

Figura 1: RMs e RIDEs Brasileiras

Fonte: Elaboração própria a partir de Garson, Ribeiro \& Rodrigues, 2010.

As funcionais são aquelas em que o fenômeno metropolitano é explícito, relacionado a dinâmicas cotidianas entre os núcleos principais e secundários; e as formais, são aquelas em que por força de legislação, tais áreas, sem que necessariamente apresentarem tais dinâmicas, foram classificadas como metrópole, (Costa, 2013). Tal situação se deve principalmente ao fato da Constituição Federal de 1988, facultar aos Estados a possibilidade de "instituição de regiões metropolitanas, aglomerações urbanas e microrregiões" (Brasil, 1988).

Na década de 1960, geógrafos brasileiros citados por Castello Branco et al (2013), chamavam a atenção para processos de "metropolização em curso no país, onde algumas cidades se espalhavam como manchas de óleo ultrapassando limites administrativos". A Carta Magna brasileira de 1967, artigo 157, § 10, promulgada durante o regime militar, vigorou no Brasil até 1985, e atentava ao fenômeno, atribuindo à União, mediante lei complementar, o poder para: “(...) estabelecer regiões metropolitanas, constituídas por Municípios que, independentemente de sua vinculação administrativa, integrem a mesma comunidade socioeconômica, visando à realização de serviços de interesse comum" (Brasil, 1967).

De tendências centralizadoras, a Carta Magna previa inclusive a possibilidade de uma mesma região metropolitana agrupar municípios de diferentes Estados da federação. No contexto, os casos da RM Rio de Janeiro, que junto a outras oito RM, foram instituídas pelas Leis Complementares 14/1973 e 20/1974, a saber: Belém, Fortaleza, Recife, Salvador, Belo Horizonte, Rio de Janeiro, São Paulo, Curitiba e Porto Alegre. Todas 
elas, segundo Galvão et al. (1969), polarizadas por uma grande cidade, com mais de 400 mil habitantes - a população de Belém e Curitiba, à época, as duas menos populosas do conjunto, e densidade demográfica igual ou superior a 500 habitantes $/ \mathrm{km}^{2}$ no seu distrito-sede e, além de funções urbanas diversificadas e especializadas. Segundo Veloso \& Trindade Jr. (2014), as principais características desse período de institucionalização das RM brasileiras são: "(...) a) o componente autoritário da intervenção, materializado na centralização de decisões na esfera federal de governo e na perda de autonomia de entes federados como Estados e municípios; b) o estabelecimento de uma estrutura institucional para planejar, financiar e executar as ações de alcance metropolitano; c) a disponibilidade de recursos financeiros que permitiram a implementação de projetos metropolitanos, especialmente nas áreas de transporte coletivo e tráfego urbano" (Veloso \& Trindade Jr, 2014:195).

Após a redemocratização e durante os trabalhos de elaboração da nova constituição, articularam-se no chamado Movimento Nacional pela Reforma Urbana, forças bastante ativas nas temáticas urbanas complementares dos anos 1980. Foram determinantes as conquistas relacionadas à ampliação do direito à cidade (Maricato, 2000), por outro lado, a condição de superação das políticas centralizadoras gerou a necessidade de mais autonomia aos Estados e municípios, algo de significativo avanço na Carta promulgada em 1988 (Caixeta, 2018). Nesse contexto, segundo Castello Branco et al (2013), a partir dos anos 1990: “(...) cada Estado tem adotado procedimentos próprios para estabelecer as suas RMs, não havendo um critério único para a criação e delimitação destas áreas em escala nacional. A própria nomenclatura da estrutura territorial estabelecida para as RMs difere de estado para estado" (Castello Branco et al, 2013:117).

A necessidade de autonomia tirou do governo central, de visão ampla, uma importante atribuição de planejamento. Entretanto, como fenômenos sociais e urbanos tendem a não respeitar limites políticos, a nova legislação extinguiu a possibilidade da existência de regiões metropolitanas englobando municípios de diferentes Estados. Como resposta, aborda Castello Branco et al (2013): "(...) foi criada (...) uma nova unidade territorial, as regiões integradas de desenvolvimento (Rides), (...) por decreto e legislação complementar em nível federal" (Castello Branco et al, 2013:117).

Devolve-se assim, por decreto, parte da responsabilidade ao governo central, criando categoria distinta de aglomeração urbana, com o mesmo objetivo: realizar o planejamento conjunto de serviços públicos de interesse comum, em especial a infraestrutura e a geração de empregos. A gestão que deveria contribuir para o crescimento e desenvolvimento das metrópoles, tem na verdade agravado a polarização espacial dos territórios de grandes necessidades e investimentos restritos, gerando fragilidades e baixa efetividade do arranjo institucional. Assim coloca em cheque o sentido real da institucionalização metropolitana (Costa, 2013), que conforme o art. 25, § $3^{\circ}$ da Constituição Brasileira, todavia, já não garante o ordenamento das chamadas funções sociais de interesse comum (Brasil, 1988).

Conforme Drummond \& Silveira (2013), função pública de interesse comum é "a atividade ou o serviço cuja realização por parte de um município, isoladamente, seja inviável ou cause impacto nos outros municípios integrantes da região metropolitana" e que por isso, "devem ser conduzidas de forma compartilhada" por possuírem "repercussões diretas no território". Estão entre elas, as funções de mobilidade, saneamento básico, aproveitamento dos recursos hídricos, preservação ambiental, habitação, rede de saúde e desenvolvimento socioeconômico de aglomerações urbanas metropolitanas.

Entre outras formas de organização e funções sociais e espaciais que se multiplicam e afloram nas metrópoles do nosso tempo, as funções cotidianas de deslocamento, (Pinheiro et al, 2013), estão entre as mais percebíveis pelo cidadão metropolitano, com volumosos fluxos migratórios diários, devidos a concentrações de emprego no centro e marginalização das habitações na periferia.

\section{METRÓPOLES DIFUSAS}

Para além da visão dicotômica centro-periferia existem outras definições sobre a cidade contemporânea. Zygmunt Bauman (2001) a define como uma cidade líquida, que se dilui enquanto história, essência e forma espacial, suscitando reações entre apoio e rejeição. Outros a veem como uma nova forma de cidade: cidade difusa, para Bernardo Secchi (2009), Nestor Goulart Reis (2006) e Francesco Indovina (2004); cidade genérica sem história, composta por espaços residuais - "espaço lixo", que vivem da espetacularização da imagem como mercadoria -, congestionada de gente, para Rem Koolhaas (2010); cidades policiadas, fortificadas, privatizadas, mercantilizadas, em condomínios fechados, segregadas socialmente e apocalípticas, para Edward Soja (2000) e Mike Davis (2009). 
Todos estes conceitos e formas se encontram diluídos nas metrópoles brasileiras, porém ainda é muito forte e perceptível nessas cidades o modelo do núcleo e sua periferia. A realidade de país subdesenvolvido, de instituições frágeis e contaminadas por interesses além do coletivo, destina ricos e pobres a ocuparem locais diferentes (Secchi, 2015), facultando aos pobres as piores ou mais distantes localizações, e aos ricos as áreas mais centrais. Especialmente nos casos estudados neste artigo, regiões metropolitanas marcadas pela segregação socioespacial, a visão centro periferia ainda persiste como fenômeno fundamental, justificativa pela qual ainda cabe compreendê-la. É como destaca Indovina (2003): "nada na Europa é confrontável com as cidades de Terceiro Mundo (...)".

Voltando a questão do investimento, para atendimento de funções metropolitanas complexas e impactantes, se nem mesmo a distribuição dos recursos de forma uniforme é garantia de superação dos problemas, o que dizer quando há dificuldades em fazê-lo? No Brasil observa-se o direcionamento dos investimentos para ocorrências pontuais e de visibilidade política, sem interesse pela superação de um de seus maiores problemas, a desigualdade social e seu rebatimento no espaço.

Brasília e Belém são duas metrópoles brasileiras, a polarizar, segundo parâmetros globais e especificidades locais, diversos outros núcleos urbanos, irradiando por suas periferias padrões de crescimento urbano, dispersando gente, concentrando riqueza e pobreza em campos opostos, adensando serviços em seus núcleos principais. Em Brasília tem-se um território disperso, muito polarizado no Plano Piloto de Brasília, sede do Governo Brasileiro, se espalhando por municípios muito díspares em três Estados. Enquanto Belém, a capital do Estado do Pará, na Amazônia Oriental, nota-se adensamento no entorno do centro e poucas relações de interdependência de atividades, funções e grupos.

\section{BELÉM, CIDADE HISTÓRICA PRECARIZADA E APARTADA DE SUA PERIFERIA}

Criada pela Lei Complementar 14, de 8 de junho de 1973, a Região Metropolitana de Belém é formada por sete municípios: Ananindeua, Marituba, Benevides, Santa Barbara, Santa Izabel, Castanhal, e a capital do Estado, Belém (Figura 2). Fundada em 1616 por portugueses para defesa do território face às pretensões de outras potencias européias, Belém desempenhou no período colonial brasileiro o papel de "cidade primaz na rede urbana regional, a partir da qual se deu a conquista do território amazônico" (Trindade Jr., 1997:12).

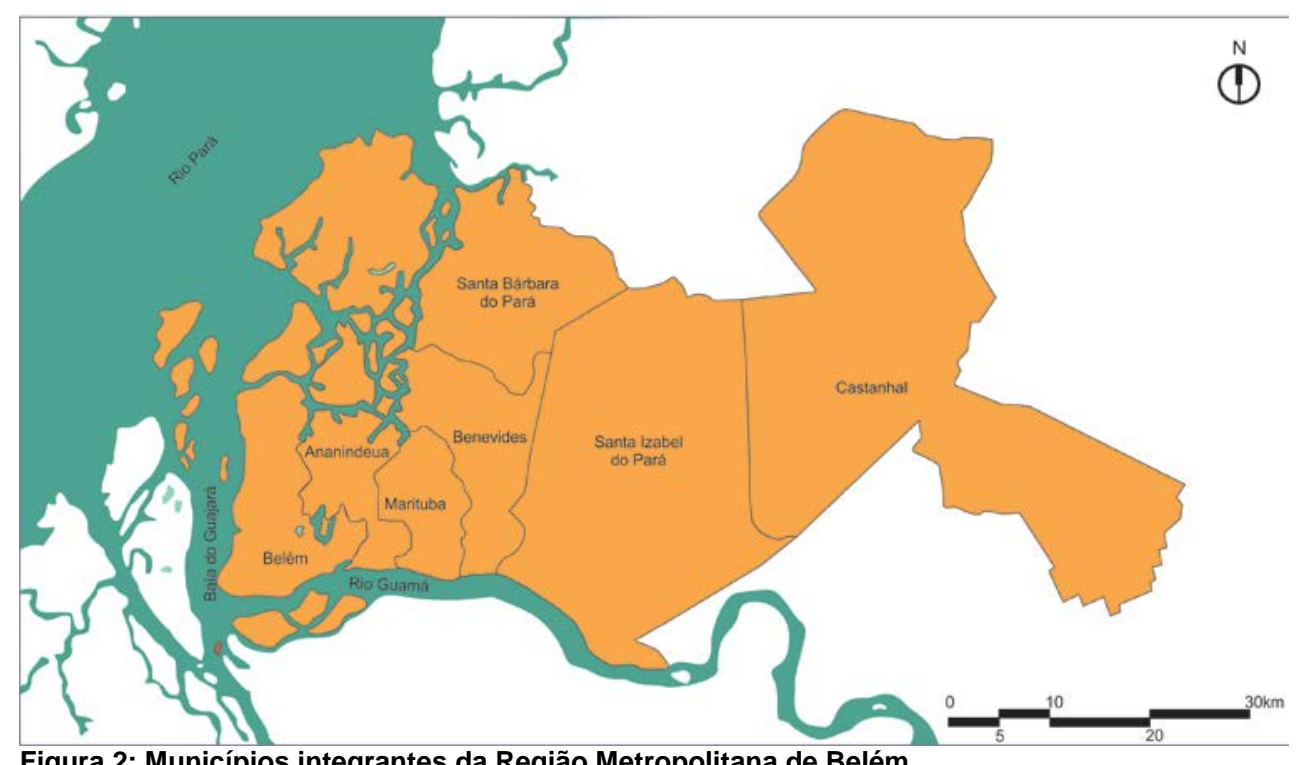

Figura 2: Municípios integrantes da Região Metropolitana de Belém Fonte: Elaboração própria a partir de Pinheiro et al, 2013.

Com um contingente populacional de 2.275 .000 habitantes (IBGE, 2010), a Região Metropolitana de Belém possui taxas de urbanização superiores a $60 \%$ e, entre 2000 e 2010, a taxa de urbanização da população superou os $90 \%$, havendo em termos absolutos, uma elevação de $25,6 \%$ no decênio $2000-2010$ (Pinheiro et al, 2013). Em 2010, a capital concentrava, $61,39 \%$ dos domicílios da RM, seguida Ananindeua, com 20,94\%, além disso, como será visto adiante, esses municípios são os que possuem as mais elevadas densidades demográficas, isso em função da reduzida área territorial, se comparada aos demais municípios (Pinheiro et al, 2013). Outras particularidades do território da RM Belém são a subnormalidade nas áreas de baixadas e a metropolização dispersa, frutos de processos de evolução e crescimento urbano. Em 2011 a região possuía 
aproximadamente $50 \%$ de sua população residente em aglomerados subnormais ${ }^{1}$, localizados principalmente em áreas de baixadas, o que corresponde no território nacional a 10\% desse tipo de ocupação (IBGE, 2010b).

Segundo Trindade Jr. (1997), até a primeira metade do século XX: "(...) a evolução do espaço urbano de Belém demonstra (...) uma clara tendência de não ocupação dos terrenos pantanosos. Priorizou-se, portanto, a ocupação dos terrenos de cotas mais elevadas" (Trindade Jr., 1997:43). Essa ocupação durante muito tempo esteve cargo do Estado, entretanto, a partir da metade do século, devido principalmente a perda da primazia regional na Amazônia, decorrente entre outros fatores, da industrialização de Manaus e pela decadência das atividades agropecuárias, que desencadearam correntes migratórias campo-cidade, a capital do Estado passa a contar com outros dois agentes principais na produção do espaço urbano: o capital imobiliário e as camadas populares (Trindade Jr., 1997). O segundo grupo, ao ocupar o território de maneira espontânea, buscando garantir condições de vida, viram nas baixadas, até então espaços pouco valorizados, de alagamento sazonal, destinadas a atividades agropastoris: "(...) mais que uma simples solução de emergência para o problema da moradia, mas também uma estratégia de sobrevivência na grande cidade" (Trindade Jr., 1997:48).

É como relata Maricato (1996), aos pobres têm sido destinados os espaços que sobram da "cidade regulada", quase sempre "autoconstruídos" em áreas vedadas para o estabelecimento dos mercados formais (beiras de córregos, áreas rurais ou de preservação), sendo então objeto da gestão cotidiana. Um resultado do subdesenvolvimento da economia brasileira, a urbanização com baixos salários e da estratégia da "Não Ação" nas cidades. Entretanto, segundo (Pinheiro et al, 2013), as baixadas, apesar de serem a segunda opção, àquela altura do tempo, tinham condições melhores de acessibilidade espacial diante da "barreira" formada por grandes glebas de terras federais, que limitava o avanço da ocupação urbana de Belém. O que não ocorreu sem conflitos entre os autodeclarados proprietários e os novos ocupantes (Trindade Jr.,1997), conflitos esses, que iam sendo mediados pelo Estado enquanto a cidade crescia de dentro para fora. Nas décadas de 1970 e 1980 foram realizadas diversas intervenções e obras de drenagem que aceleraram o aumento da densidade demográfica das áreas centrais.

Já no início deste século, Trindade Júnior (1998), Rodrigues \& Ponte (2015), Pinheiro et al (2013) concordam sobre a tendência de dispersão da população no território metropolitano de Belém, resultante da implantação de conjuntos habitacionais e condomínios fechados, ao longo de eixos de expansão segregados e desarticulados (Rodovias Augusto Montenegro e BR-316), para além da barreira ou cinturão institucional citado anteriormente, resultando um processo de "metropolização dispersa" (Trindade Júnior,1998). Entretanto, essa expansão não é acompanhada da criação de novas centralidades ou subcentralidades econômicas, que representam distribuição espacial de oportunidades e riquezas social, mas sim da expansão da moradia precária, formando-se um eixo norte de penetração do território continental de Belém, o que aumenta as distâncias, a necessidade de deslocamentos cotidianos e deficiências nos sistemas de transporte (Rodrigues \& Ponte, 2015).

Assim, a RM Belém, indica, a configuração de um núcleo urbano denso, com índices de subnormalidade elevados e conurbado aos municípios de Belém. Marituba e Ananindeua, estão conectados aos demais núcleos por rodovias em que se desenvolve a metropolização dispersa, associados a baixas coberturas de saneamento e infraestrutura, localizadas longe dos contingentes de emprego. Destacam Veloso \& Trindade Jr, um tecido urbano caracterizado por uma "malha urbana de dupla configuração (conurbada e descontínua) e unificada por sistema de fluxos regulares" (Veloso \& Trindade Jr, 2014:193), alcançando uma área de aproximadamente $3.500 \mathrm{~km}^{2}$ (Figura 3), e também Pinheiro et al (2013: 53): "Como parece ser próprio da lógica de concentração do sistema econômico, persiste a densidade mais alta de empregos e infraestrutura na mancha mais central de Belém, e a expansão das ocupações precárias e dos conjuntos habitacionais segregados nas áreas de urbanização recente em eixos rodoviários. Mesmo em termos da morfologia urbana, notam-se aspectos de heterogeneidade da ocupação; a cidade revela-se mais integrada e compacta nas áreas de ocupação secular, enquanto nas zonas de expansão a desarticulação da malha viária é acompanhada de dinâmicas de segregação socioespacial e de carência de infraestrutura urbana".

\footnotetext{
${ }^{1}$ Segundo o IBGE, aglomeração subnormal é o conjunto constituído por 51 ou mais unidades habitacionais caracterizadas por ausência de título de propriedade e pelo menos uma das características abaixo: irregularidade das vias de circulação e do tamanho e forma dos lotes e/ou carência de serviços públicos essenciais como coleta de lixo, rede de esgoto, rede de água, energia elétrica e iluminação pública (IBGE, 2010)
} 


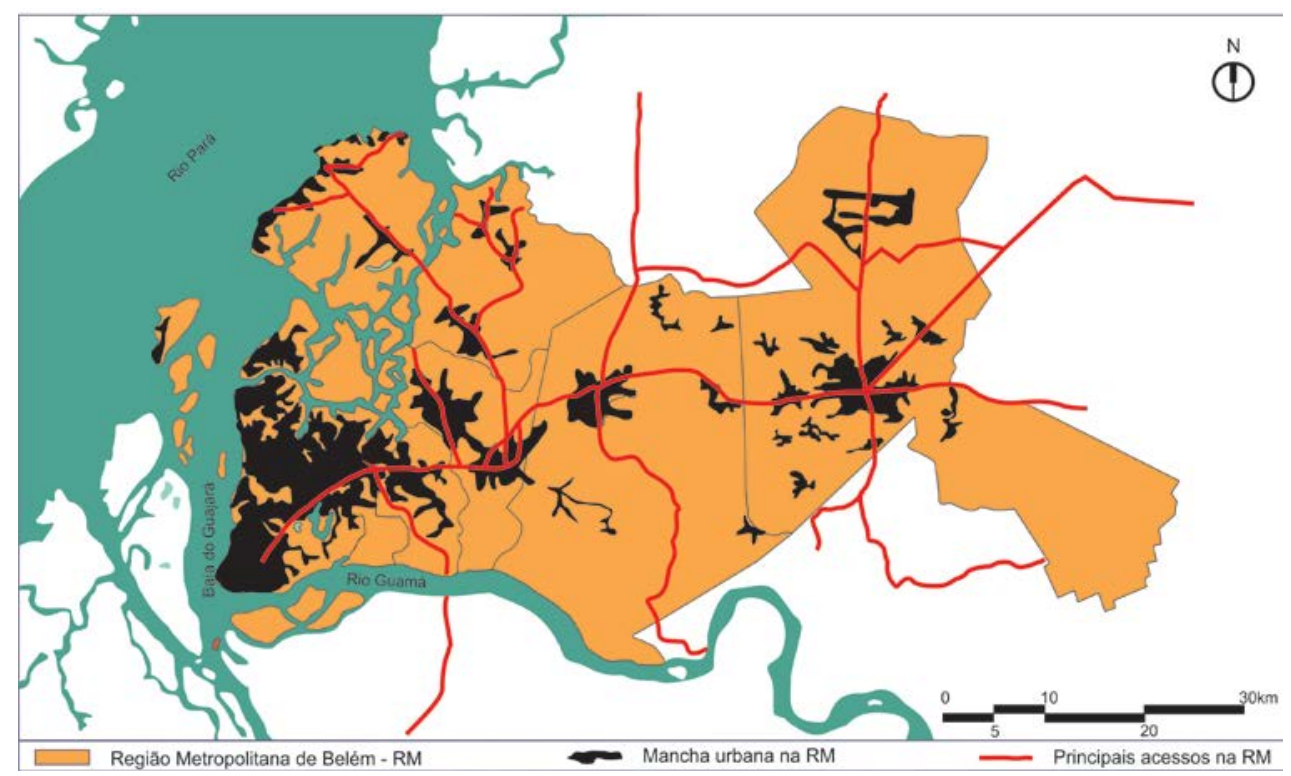

Figura 3: Mancha Urbana conurbada e descontínua, Região Metropolitana de Belém

Fonte: Elaboração própria a partir de Pinheiro et al, 2013.

Outro aspecto a destacar sobre a RM Belém é sua condição de metrópole terciária, ou seja, sua base econômica concentrada no setor de comércio e serviços, reflexo de sua tradição comercial, posição geográfica, e de sua política nacional de desenvolvimento amazônico. Essa política, desde 1967, atribui a Manaus, o papel de Zona Franca Industrial e a Belém o de concentrar a maioria das sedes das instituições públicas da região (Browder \& Godfrey, 2006), tornando-a um centro administrativo regional das políticas e dos programas relacionados à região. Essa opção, todavia, a longo prazo foi insuficiente, e determinante para a relativa perda de influência como principal aglomeração urbana da Amazônia e também como metrópole nacional, como outrora fora: "Desse modo, a cidade de Belém e seu entorno metropolitano consolidaram-se no final do século XX como um aglomerado urbano de influência regional, e não mais como metrópole nacional; este papel seria desempenhado por outras metrópoles, como Salvador e Recife" (Pinheiro et al, 2013:54).

Essa transformação foi captada pelo estudo intitulado Região de Influência de Cidades - REGIC, publicado em 2007 pelo Instituto Brasileiro de Geografia e Estatística - IBGE, que analisou as redes urbanas do território brasileiro à época. Em estudo anterior de 1966, Manaus subordinada a Belém, e Brasília, uma recém-criada capital administrativa, o REGIC/2007 aponta ascensão em relação ao quadro existente na metade do século XX (IBGE, 2007).

\section{BRASÍLIA, CAPITAL SIMBÓLICA E PROTEGIDA DE SUA PERIFERIA}

Brasília é o grande centro de coordenação do País, a capital federal do Brasil, sede da grande maioria das instituições públicas federais (IBGE, 2007:15). Fundada em 1960, evoluiu de canteiro de obras para uma grande cidade em menos de 60 anos, e ao contrário de Belém, seu núcleo original nunca foi denso, próprio de sua concepção original modernista.

Num primeiro momento, houve a implantação da cidade, como base física, às margens do lago artificial do Paranoá, por meio da instalação dos equipamentos básicos da administração federal: palácios, ministérios, além de outros edifícios e infraestruturas básicas, o chamado Plano Piloto de Brasília, no centro do território do novo Distrito Federal. Isso representou, migrações em massa provenientes das regiões mais pobres do país e inúmeras ocupações populares nas proximidades do núcleo original.

Quase que simultaneamente, essas ocupações eram sistematicamente transferidas para áreas mais distantes, além da chamada Estrada Parque Contorno - EPCT, com a justificativa de se proteger as condições ambientais da nova capital (IPEA/UnB/UFRJ, 2002), a despeito do grande desmatamento do cerrado natural. Essa estrada tornou-se peça básica para a segregação espacial dos novos centros urbanos a serem criados, e passou a constituir-se o anel sanitário de Brasília. Dessa maneira se deram as primeiras ocupações periféricas, ainda sem expansão significativa da população. 
Já nas décadas de 1970 e 1980 ocorre a efetiva ocupação do Plano Piloto e expressiva expansão das primeiras cidades periféricas: de Taguatinga, Gama e Sobradinho, além da criação da Ceilândia, resultado tanto da oferta de habitações pelo poder público, quanto de ocupações de fundos de lotes e invasões.

Acontece também neste momento a consolidação do Lago Sul e Lago Norte, do outro lado do espelho d'água, previstos no plano original, que agrupados ao Plano Piloto neste trabalho, formam o núcleo histórico da cidade, de onde nas décadas seguintes partem as grandes obras viárias de porte a conectar a periferia dispersa que não parava de crescer, e que em meados dos anos 1980 já atingia terrenos do Entorno do Distrito Federal, Estado de Goiás, onde o mercado imobiliário atendia as altas demandas existentes (Bitencourt, 2005). Ocorre também a criação de diversas localidades urbanas já dentro dos limites da EPCT, por sobre as áreas verdes até então disponíveis, inclusive pela flexibilização legislação urbanística, permitindo o reparcelamento de terrenos de chácaras do chamado cinturão verde da cidade.

Consolida-se o adensamento urbano dos municípios da região do Entorno, dando início à aglomeração metropolitana propriamente dita, tal como se apresenta nos dias atuais. Alguns municípios já existiam e eram centros secundários de base agroeconômica (Luziânia, Formosa e Planaltina) que, em função de sua proximidade com o Distrito Federal, serviram de apoio para a construção da cidade. Outros surgiram do desmembramento do território dos municípios existentes em função da relevância que adquiriram suas áreas urbanas: Cidade Ocidental, Valparaíso de Goiás, Novo Gama Águas Lindas e Planaltina de Goiás, todos implantados do final dos 1980 aos 1990.

São da mesma época diversos assentamentos privados horizontais voltados às mais diversas faixas de renda, chamados condomínios. Esses loteamentos nasciam à medida que o mercado imobiliário se aproveitava da pluralidade de regimes jurídicos das terras que constituíram o quadrilátero do Distrito Federal: terras não discriminadas, terras públicas adquiridas em comum e não submetidas a um processo legal de divisão ou arrendadas para uso rural (IPEA/UnB/UFRJ, 2002). Muitas desses condomínios se instalaram sem nenhum critério, em áreas de interesse e preservação ambiental, aproveitando-se da falta de fiscalização. Hoje, ocupam grandes porções do território do Distrito Federal, concentrando-se nas porções Nordeste e Sudeste.

Em 1987 o projeto urbanístico de Brasília foi tombado como patrimônio histórico e artístico nacional, por meio da portaria 314/IPHAN, que atribui ao conjunto a organização em escalas, entendidas como relações existentes entre a cidade seus elementos e seus usuários (Gorovitz,1985). Se por um lado o tombamento de Brasília buscava garantir que gerações futuras possam conhecer e vivenciar sua experiência urbanística típica do urbanismo do século XX, por outro, ela cristalizava seu núcleo original, mantendo também características controversas, entre elas a segregação espacial da população migrante. "Os milhares de trabalhadores atraídos para o Distrito Federal pela construção da Capital não tiveram acesso aos tipos edilícios propostos no Plano Piloto. No Brasil, como em todo o mundo, a urbanização da população migrante é um longo processo no tempo, iniciando-se com os mais elementares abrigos, que vão passando por melhorias progressivas na medida das possibilidades crescentes (quando o caso) das pessoas que os constroem" (Holanda, 2001:61). As sucessivas transferências de assentamentos centrais para as periferias, para além da EPCT, prova e indica uma preocupação com o embelezamento do centro, "mantido agradável", protegido, enquanto a "feiura" é mantida "afastada" (Ribeiro, 2011).

A partir de 2000, segundo Nogales \& Gomes (2012), o Brasil e suas grandes cidades já experimentam a redução dos níveis de natalidade e mortalidade que conduziram à estagnação das taxas de crescimento populacional, entretanto, diferentemente, talvez porque as áreas periféricas continuariam crescendo, Brasília ainda investe obras viárias de porte possibilitando acesso as essas localidades. Assim, se estimula cada vez mais o uso do transporte individual e a frota de veículos particulares no Distrito Federal atinge a marca de um milhão de unidades em 2008, não obstante ao início da operação do Metrô/DF. Partindo da Rodoviária do Plano Piloto, o sistema atinge as localidades do Guará, Águas Claras, Taguatinga e Ceilândia, até hoje insuficiente no atendimento da demanda. Em 2008 ele atendia aproximadamente 15\% da demanda do Serviço Básico de Transportes Coletivos, atendida majoritariamente por ônibus, cerca de $67 \%$ (DISTRITO FEDERAL, 2009b).

Esses processos resultam em uma configuração dispersa, descompactada que alcança uma área de aproximadamente $56.000 \mathrm{~km}^{2}$ (IBGE, 2010), considerando-se a RIDE DF - Região Integrada de Desenvolvimento do Distrito Federal e Entorno, criada pela Lei Federal Complementar no 94 de 19/02/1998, unindo do Distrito Federal e vinte e dois municípios goianos e mineiros, com o objetivo de estabelecer mecanismo institucional para tratar os problemas regionais (Figura 4). Essa estrutura, como é de se esperar, apresenta dificuldades para gerenciar seus serviços públicos, transporte, por exemplo. 


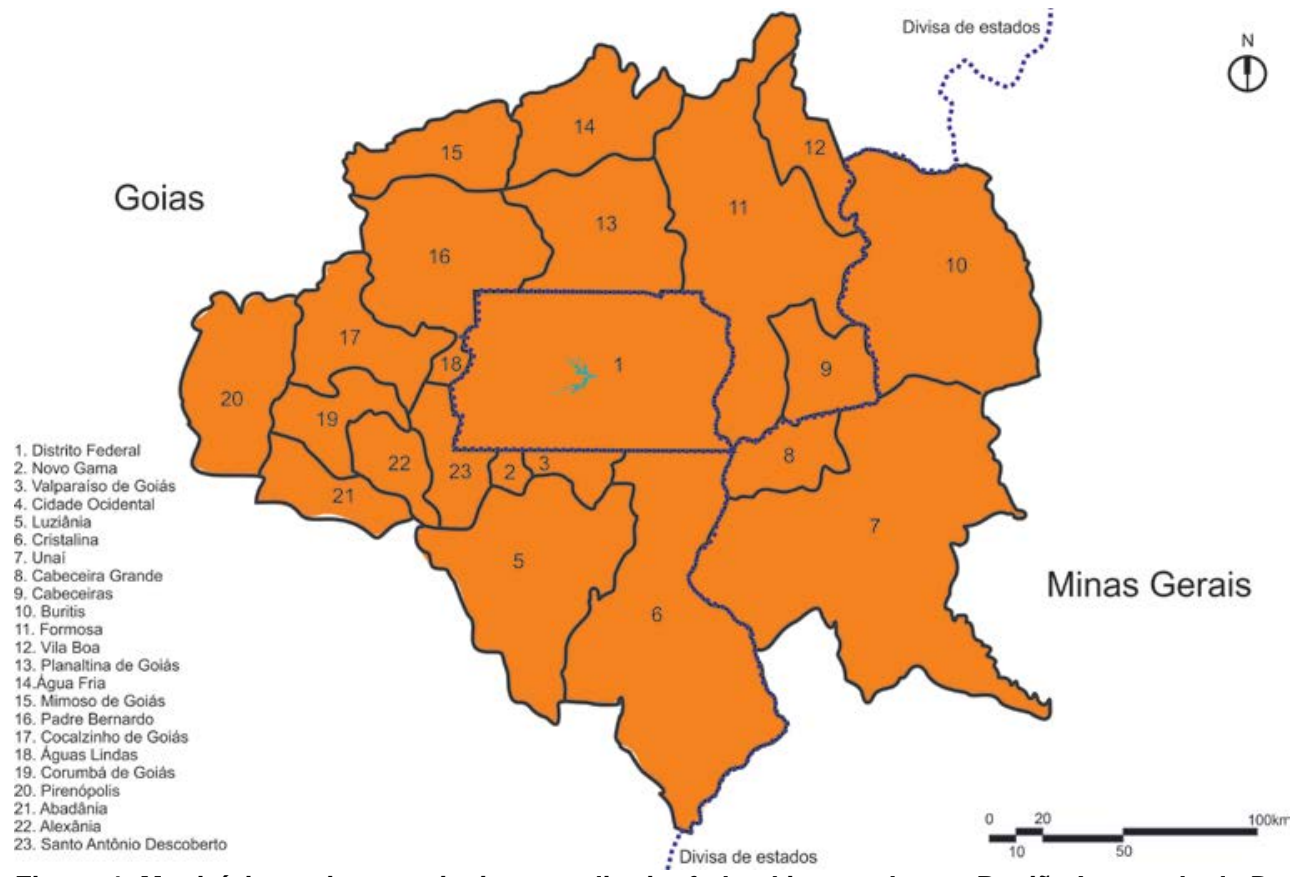

Figura 4: Municípios goianos, mineiros e o distrito federal integrados na Região Integrada de Desenvolvimento do Distrito Federal e entorno, RIDE DF

Fonte: Elaboração própria.

No Distrito Federal as características operacionais praticadas denunciam isso: modelo operacional porta-aporta, com sobreposição de linhas, baixa produtividade e de qualidade dos serviços oferecidos, frota antiquada, elevados intervalos entre as viagens, alto custo de tarifa, descentralização e desconexão dos serviços, sem falar nas deficiências de acessibilidade, quanto mais distante se está do núcleo primaz ou dos principais corredores. São limitadas as possibilidades de integração e os projetos necessários não avançam, levando à população uma percepção ruim tanto da qualidade quanto da confiabilidade do sistema, isso num território com populações habitando a periferia e postos de trabalho concentrados no centro.

A RIDE DF possui disparidades entre os municípios: distintas as matrizes econômicas, padrões de crescimento populacional, densidade, atendimentos de serviços, entre outros, sendo as relações metropolitanas com o Distrito Federal mais intensas em alguns municípios, que sofrem os efeitos polarizantes da capital (Sampaio et al, 2013). Nesse caminho, a CODEPLAN - Companhia de Desenvolvimento do Distrito Federal, para realização da Pesquisa Metropolitana por Amostra de Domicílios - PMAD (Distrito Federal, 2013 e 2015) utiliza além do Distrito Federal, doze municípios da periferia: Águas Lindas de Goiás, Alexânia, Cidade Ocidental, Cristalina, Cocalzinho de Goiás, Formosa, Luziânia, Novo Gama, Padre Bernardo, Planaltina, Santo Antônio do Descoberto e Valparaíso de Goiás, totalizando $31.836 \mathrm{~km}^{2}$, ao qual denomina Área Metropolitana de Brasília (Figura 5).

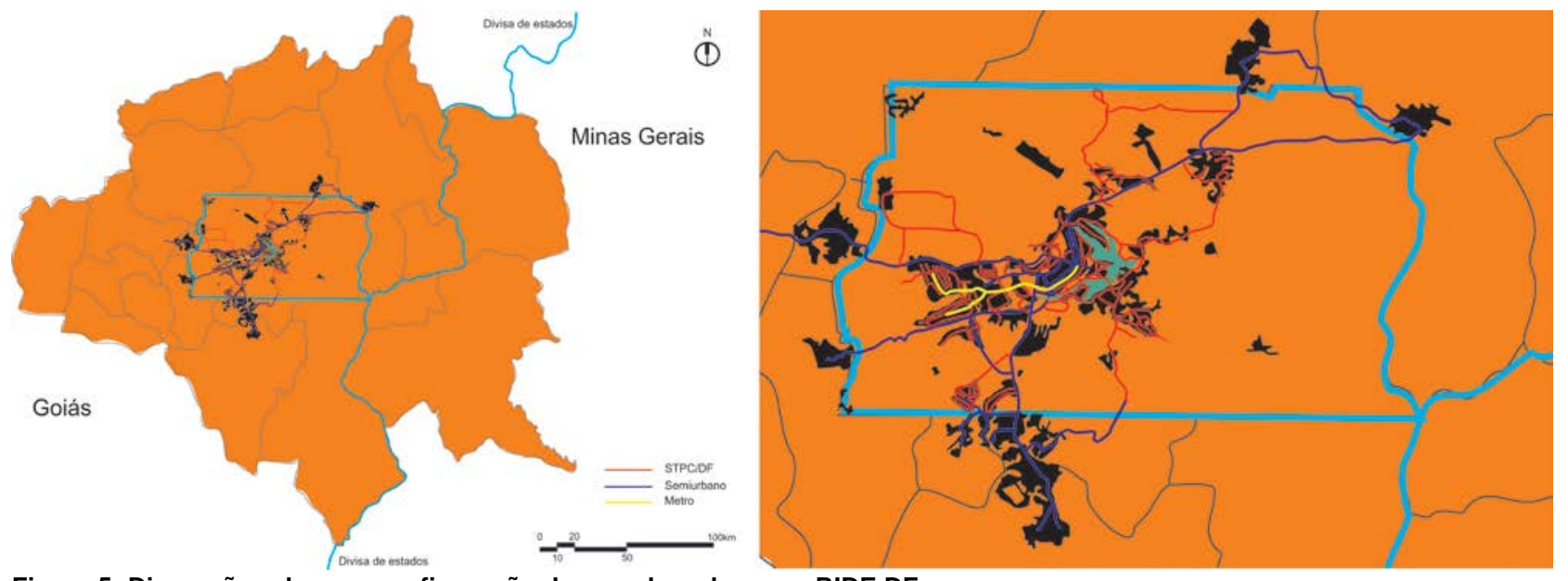

Figura 5: Dispersão urbana e configuração da mancha urbana na RIDE DF

Fonte: Elaboração própria a partir de PDTU (DISTRITO FEDERAL, 2009) 


\section{MÉTODO ADOTADO}

O desenho da CODEPLAN se aproxima da mancha urbana, cujos limites este artigo tentará definir na sequência, bem como os limites da RM Belém, uma vez que compreender o contorno da metrópole parece ser um importante passo para gestão desse tipo de fenômeno urbano chamado metrópole.

Segundo Holanda (2001), fatores morfológicos que descrevam a própria forma da cidade no que diz respeito ao problema da compacidade, ou seja, não contribuem para explicar a excentricidade de Brasília. Nesse contexto, não obstante aos papéis distintos na rede urbana brasileira e dos níveis de precariedade e segregação espacial, o que mais diferencia as duas metrópoles? Seus padrões de densidade e dispersão urbanas. Nesse texto vamos nos atentar e elas, além de características relacionadas ao crescimento populacional e viagens metropolitanas.

O Quadro 1 apresenta dados secundários, sobre o espaço metropolitano de Belém e Brasília, conforme definido pela legislação relacionada: Região Metropolitana de Belém, Lei Complementar 14/1974 e Região Integrada de Desenvolvimento do Distrito Federal e Entorno, conforme Lei Federal Complementar no 94/1998. Entre as variáveis escolhidas estão: população, área, crescimento populacional na última década e distância e tempo deslocamento até o centro de cada metrópole, medido em horário de pico manhã (8 horas). As informações são pertinentes aos Municípios e Regiões Administrativas (RA) do Distrito Federal, já que que não existem municípios ali, compondo o espaço e as dinâmicas metropolitanas das cidades estudadas.

A partir desses dados apresentados, é possível obter outros dois indicadores: a densidade populacional e a dispersão urbana, e deste conjunto, confrontar aos territórios formais outros dois territórios hipotéticos, os quais aqui, denomina-se a metrópole funcional.

Classicamente a densidade é dada pelo número de residentes relacionado à área em que se encontram distribuídos. Ribeiro (2008) destaca a diferença entre densidade populacional (habitantes $/ \mathrm{km}^{2}$ ou /hectares) e a densidade residencial (domicílios $/ \mathrm{km}^{2}$ ou /hectares). O primeiro a tratar a quantidade de pessoas por área e o segundo, a densidade construtiva por área, sendo o primeiro mais adequado quando se tem em conta a população no âmbito da pesquisa. Jacobs (2001: 222), por sua vez, acrescenta: "Todos sabem que uma quantidade imensa de pessoas se concentra nos centros das cidades e que, se não houvesse tal concentração, não haveria centro urbano que se prezasse - certamente não com a diversidade típica dos centros".

Mas não basta a um centro que ele exista, ele tem de ser denso. Muitos centros em áreas densas são desejáveis, poucos centros em baixa densidade é o que se deve evitar no urbanismo contemporâneo. Como medir?

$$
D=P / A
$$

(onde $\mathrm{P}=$ população da unidade de pesquisa e $\mathrm{A}=$ área total da unidade de pesquisa).

Na cidade dispersa, verifica-se a atração populacional a um mesmo ponto, conhecido CBD (Central Business District), a partir de diferentes pontos da malha urbana. Morar perto desses pontos é, normalmente mais caro, daí a necessidade de deslocamentos e consequentemente mais recursos pessoais e corporativos gastos neles, também encarecendo a infraestrutura de serviços básicos.

Como medir? Para Holanda (2001) e Ribeiro (2008), a partir de Bertaud \& Malpezzi (2003), é possível apontar o índice de dispersão, também utilizada como reflexo da ocorrência de espaços não ocupados no tecido urbano, o que obviamente, implica maiores custos socioeconômicos. Citando Holanda (2001:67), "a idéia é simples: a forma da cidade analisada é comparada à forma circular de uma cidade hipotética de área equivalente. A fórmula para calcular o índice de dispersão, adaptada para efeito de maior clareza, é a seguinte":

$$
\rho=\frac{\Sigma i d i p i}{P C}
$$

"Onde o símbolo correspondente à letra grega "rho" $\rho$ - é o índice de dispersão; "d" é a distância do centróide de cada setor urbano ao centro da cidade; "p" é a população de cada setor urbano; "P" é a população urbana total; e " $\mathrm{C}$ " é a distância média dos pontos de um círculo, de área equivalente à da cidade analisada, ao seu centro (que é igual a 2/3 de seu raio, valor obtido por meio de cálculo integral)" (Holanda, 2001:67). 
Como os cálculos elaborados por esses dois autores se referem ao total das áreas urbanas estudadas em cada caso $^{2}$, restringimos a formula à:

$$
\rho=\frac{d i p i}{10 P C}
$$

Dessa maneira, obtemos resultados desagregados por município, conforme o Quadro 2. 


\begin{tabular}{|c|c|c|c|c|c|}
\hline & $\begin{array}{l}\text { População } \\
2010 \\
\text { (IBGE) }\end{array}$ & $\begin{array}{l}\text { Areas } \\
\text { (IBGE) }\end{array}$ & $\begin{array}{c}\text { Crescimento } \\
\text { populacional } \\
\text { 2000-2010 } \\
\text { (IBGE) }\end{array}$ & $\begin{array}{c}\text { Distância até o } \\
\text { centro da } \\
\text { metrópole } \\
\text { [Google Maps) }\end{array}$ & $\begin{array}{c}\text { Tempo } \\
\text { deslocamento } \\
\text { periferia centro } \\
\text { (Google Maps) }\end{array}$ \\
\hline RM Belém - Municípios & & $\begin{array}{l}\text { Areas } \\
\text { (IBGE) }\end{array}$ & & & \\
\hline ANANINDEUA & 471.980 & 190,45 & $19,90 \%$ & 18,30 & 46,00 \\
\hline BELÉM & 1.393 .399 & $1.059,46$ & $8,80 \%$ & 0,00 & 0 \\
\hline BENEVIDES & 51.651 & 187,82 & $45,30 \%$ & 32,30 & 56,00 \\
\hline CASTANHAL & 173.149 & $1.028,89$ & $28,70 \%$ & 73,40 & 94,00 \\
\hline MARITUBA & 108.246 & 103,34 & $45,40 \%$ & 23,40 & 49,00 \\
\hline SANTA BÁRBARA DO PARÁ & 17.141 & 278,15 & $50,70 \%$ & 47,80 & 74,00 \\
\hline SANTA IZABEL DO PARÁ & 59.466 & 717,66 & $37,60 \%$ & 45,20 & 86,00 \\
\hline TOTAIS & 2.275 .032 & 3.566 & & & \\
\hline \multirow[t]{2}{*}{ MÉDIAS } & & & $44,15 \%$ & 34,34 & \\
\hline & $\begin{array}{l}\text { População } \\
2010 \\
\text { (BBGE) }\end{array}$ & $\begin{array}{c}\text { Areas } \\
\text { (Anuário DF) }\end{array}$ & \begin{tabular}{|c|} 
Crescimento \\
populacional \\
2000-2010 \\
(IBGE)
\end{tabular} & \begin{tabular}{|c|} 
Distância até o \\
centro da \\
metrópole \\
(Google Maps)
\end{tabular} & \begin{tabular}{|c|} 
Tempo \\
deslocamento \\
periferia centro \\
(Google Maps)
\end{tabular} \\
\hline RIDE - Região Administrativa DF & & $\begin{array}{l}\text { Areas } \\
\text { (IBGE) }\end{array}$ & & & \\
\hline Gama & 137.017 & 276,34 & $5,40 \%$ & 35 & 40 \\
\hline Taguatinga + Aguas Claras + Vicente Pires & 378.133 & 121,55 & $55,51 \%$ & 25 & 31 \\
\hline Brazlândia & 50.454 & 474,83 & $-4,25 \%$ & 52 & 48 \\
\hline Sobradinho + Sobradinho II + Varjão & 146.050 & 572,59 & $13,17 \%$ & 25 & 32 \\
\hline Planaltina & 164.391 & $1.534,69$ & $11,78 \%$ & 42 & 48 \\
\hline Paranoá + Itapoã & 111.533 & 853,33 & $103,05 \%$ & 35 & 30 \\
\hline Núcleo Bandeirante + Park Way & 24.097 & 80,43 & $-33,87 \%$ & 15 & 26 \\
\hline Ceilândia & 402.080 & 230,33 & $17,22 \%$ & 33 & 38 \\
\hline Guará + SIA + SCIA & 127.276 & 119,86 & $10,49 \%$ & 12 & 24 \\
\hline Samambaia & 189.144 & 105,7 & $16,04 \%$ & 35 & 37 \\
\hline Santa Maria & 114.496 & 215,86 & $16,10 \%$ & 39 & 36 \\
\hline São Sebastião + Jardim Botanico & 106.173 & 303 & $65,40 \%$ & 30 & 28 \\
\hline Recanto das Emas & 112.055 & 101,22 & $20,49 \%$ & 30 & 39 \\
\hline Riacho Fundo I + Riacho Fundo II & 71.901 & 56,02 & $73,77 \%$ & 20 & 36 \\
\hline Candangolândia & 15.814 & 6,61 & $1,18 \%$ & 15 & 22 \\
\hline Nucleo histórico (Brasilia+ Lago Sul+ Lago Norte+ Cruzeiro+Sudoeste/Octogonal) & 332.238 & 727,6 & $5,20 \%$ & 0 & 0 \\
\hline população rural estimada (4\% - IBGE) & 87.308 & & & & \\
\hline \multirow{2}{*}{ TOTAIS - DISTRITO FEDERAL } & 2.570 .160 & $5.780,00$ & $25,79 \%$ & & \\
\hline & $\begin{array}{l}\text { População } \\
2010 \\
\text { (IBGE) }\end{array}$ & $\begin{array}{l}\text { Areas } \\
\text { (IBGE) }\end{array}$ & $\begin{array}{c}\text { Crescimento } \\
\text { populacional } \\
\text { 2000-2010 } \\
\text { (IBGE) }\end{array}$ & $\begin{array}{c}\text { Distância até o } \\
\text { centro da } \\
\text { metrópole } \\
\text { (Google Maps) }\end{array}$ & \begin{tabular}{|c|} 
Tempo \\
deslocamento \\
periferia centro \\
(Google Maps)
\end{tabular} \\
\hline \multicolumn{6}{|l|}{ RIDE - Municípios GO } \\
\hline ABADIÂNIA & 15.757 & $1.045,13$ & $37,59 \%$ & 119,2 & 96 \\
\hline AGUA FRIA & 5.090 & $2.029,42$ & $13,90 \%$ & 145,6 & 118 \\
\hline ÁGUAS LINDAS DE GOIÁS & 159.378 & 188,39 & $50,72 \%$ & 54 & 74 \\
\hline ALEXÂNIA & 23.814 & 847,89 & $18,79 \%$ & 93,7 & 80 \\
\hline CABECEIRAS & 7.354 & $1.126,91$ & $8,82 \%$ & 141,8 & 112 \\
\hline CIDADE OCIDENTAL & 55.915 & 389,99 & $38,48 \%$ & 51,3 & 54 \\
\hline COCALZINHO DE GOIÁS & $17.407,00$ & $1.789,04$ & $19,01 \%$ & 110,3 & 94 \\
\hline CORUMBÁ DE GOIÁS & 10.361 & $1.061,96$ & $7,05 \%$ & 130,4 & 113 \\
\hline CRISTALINA & 46.580 & $6.162,09$ & $36,53 \%$ & 136,2 & 114 \\
\hline FORMOSA & 100.085 & $5.811,79$ & $27,25 \%$ & 83,3 & 77 \\
\hline LUZIÂNIA & 174.531 & $3.961,10$ & $23,71 \%$ & 63,9 & 62 \\
\hline MIMOSO & 2.685 & $1.386,92$ & $-4,14 \%$ & 133,8 & 125 \\
\hline NOVO GAMA & 95.018 & 194,99 & $27,75 \%$ & 58,1 & 60 \\
\hline PADRE BERNARDO & 27.671 & $3.139,18$ & $28,62 \%$ & 114,9 & 101 \\
\hline PIRENOPOLIS & 23.006 & $2.205,01$ & $8,29 \%$ & 150,6 & 132 \\
\hline PLANALTINA & 81.649 & $2.543,68$ & $10,76 \%$ & 61,3 & 63 \\
\hline SANTO ANTÔNIO DO DESCOBERTO & 63.248 & 944,15 & $21,87 \%$ & 49,3 & 55 \\
\hline VALPARAISO DE GOIÁS & 132.982 & 61,45 & $40,19 \%$ & 41,3 & 40 \\
\hline \multirow{3}{*}{ TOTAIS } & 4.735 & $1.060,17$ & $44,05 \%$ & 170 & 144 \\
\hline & 1.047 .266 & 35.949 & $29,18 \%$ & & \\
\hline & $\begin{array}{l}\text { População } \\
2010\end{array}$ & Areas & \begin{tabular}{|c|} 
Crescimento \\
populacional \\
2000-2010 \\
(IBGE)
\end{tabular} & $\begin{array}{c}\text { Distância até o } \\
\text { centro da } \\
\text { metrópole } \\
\text { [Google Maps) }\end{array}$ & \begin{tabular}{|c} 
Tempo \\
deslocamento \\
periferia centro \\
(Google Maps)
\end{tabular} \\
\hline \multicolumn{6}{|l|}{ RIDE - Municípios MG } \\
\hline BURITIS & 22.737 & $5.225,19$ & $11,43 \%$ & 216 & 172 \\
\hline CABECEIRA GRANDE & 6.453 & $1.031,41$ & $-0,17 \%$ & 121 & 125 \\
\hline UNAI & 77.565 & $8.448,08$ & $10,81 \%$ & 166 & 124 \\
\hline TOTAIS & 106.755 & 14.705 & $10,21 \%$ & & \\
\hline \multicolumn{6}{|l|}{ RIDE DF } \\
\hline TOTAIS & 3.724 .181 & 56.434 & & & \\
\hline MÉDIAS & & & $22,58 \%$ & 75,13 & 69,74 \\
\hline
\end{tabular}

Quadro 1 - Dados sobre os municípios e Regiões Administrativas das RM Belém e RIDE DF

Fonte: Elaboração própria a partir de dados do IBGE, Anuário DF e Google Maps. 


\begin{tabular}{|c|c|c|}
\hline & $\begin{array}{c}\text { Densidade } \\
\text { populacional }\end{array}$ & $\begin{array}{c}\text { Dispersão } \\
\text { urbana }\end{array}$ \\
\hline \multicolumn{3}{|l|}{ RM Belém - Municípios } \\
\hline ANANINDEUA & 2478,24 & 7,59 \\
\hline BELÉM & 1315,20 & 0,00 \\
\hline BENEVIDES & 275,00 & 1,47 \\
\hline CASTANHAL & 168,29 & 11,17 \\
\hline MARITUBA & 1047,47 & 2,23 \\
\hline SANTA BÁRBARA DO PARÁ & 61,63 & 0,72 \\
\hline SANTA IZABEL DO PARÁ & 82,86 & 2,36 \\
\hline TOTAIS & 638,02 & \\
\hline \multirow[t]{2}{*}{ MÉDIAS } & 758,34 & 3,65 \\
\hline & $\begin{array}{c}\text { Densidade } \\
\text { populacional }\end{array}$ & $\begin{array}{c}\text { Dispersão } \\
\text { urbana }\end{array}$ \\
\hline \multicolumn{3}{|l|}{ RIDE - Região Administrativa DF } \\
\hline Gama & 495,83 & 9,89 \\
\hline Taguatinga + Aguas Claras + Vicente Pires & $3.110,93$ & 19,49 \\
\hline Brazlândia & 106,26 & 5,41 \\
\hline Sobradinho + Sobradinho II + Varjão & 255,07 & 7,53 \\
\hline Planaltina & 107,12 & 14,24 \\
\hline Paranoá + Itapoã & 130,70 & 8,05 \\
\hline Núcleo Bandeirante + Park Way & 299,60 & 0,75 \\
\hline Ceilândia & $1.745,67$ & 27,36 \\
\hline Guará + SIA + SCIA & $1.061,87$ & 3,15 \\
\hline Samambaia & $1.789,44$ & 13,65 \\
\hline Santa Maria & 530,42 & 9,21 \\
\hline São Sebastião + Jardim Botanico & 350,41 & 6,57 \\
\hline Recanto das Emas & $1.107,04$ & 6,93 \\
\hline Riacho Fundo I + Riacho Fundo II & $1.283,49$ & 2,97 \\
\hline Candangolândia & $2.392,44$ & 0,49 \\
\hline Nucleo histórico (Brasilia+ Lago Sul+ Lago Norte+ Cruzeiro+Sudoeste/Octogonal) & 456,62 & 0,00 \\
\hline \multicolumn{3}{|l|}{ população rural estimada (4\% - IBGE) } \\
\hline \multirow[t]{2}{*}{ TOTAIS - DISTRITO FEDERAL } & 444,66 & \\
\hline & $\begin{array}{c}\text { Densidade } \\
\text { populacional }\end{array}$ & $\begin{array}{c}\text { Dispersão } \\
\text { urbana }\end{array}$ \\
\hline \multicolumn{3}{|l|}{ RIDE - Municípios GO } \\
\hline ABADIÂNIA & 15,08 & 9,51 \\
\hline AGUA FRIA & 2,51 & 3,75 \\
\hline ÁGUAS LINDAS DE GOIÁS & 846,02 & 43,56 \\
\hline ALEXÂNIA & 28,09 & 11,29 \\
\hline CABECEIRAS & 6,53 & 5,28 \\
\hline CIDADE OCIDENTAL & 143,38 & 14,52 \\
\hline COCALZINHO DE GOIÁS & 9,73 & 9,72 \\
\hline CORUMBÁ DE GOIÁS & 9,76 & 6,84 \\
\hline CRISTALINA & 7,56 & 32,11 \\
\hline FORMOSA & 17,22 & 42,19 \\
\hline LUZIÂNIA & 44,06 & 56,44 \\
\hline MIMOSO & 1,94 & 1,82 \\
\hline NOVO GAMA & 487,29 & 27,94 \\
\hline PADRE BERNARDO & 8,81 & 16,09 \\
\hline PIRENOPOLIS & 10,43 & 17,53 \\
\hline PLANALTINA & 32,10 & 25,33 \\
\hline SANTO ANTÔNIO DO DESCOBERTO & 66,99 & 15,78 \\
\hline VALPARAISO DE GOIÁS & $2.164,07$ & 27,79 \\
\hline VILA BOA & 4,47 & 4,07 \\
\hline \multirow[t]{2}{*}{ TOTAIS } & 29,13 & \\
\hline & $\begin{array}{c}\text { Densidade } \\
\text { populacional }\end{array}$ & $\begin{array}{c}\text { Dispersão } \\
\text { urbana }\end{array}$ \\
\hline \multicolumn{3}{|l|}{ RIDE-Municípios MG } \\
\hline BURITIS & 4,35 & 30,01 \\
\hline CABECEIRA GRANDE & 6,26 & 4,77 \\
\hline UNAI & 9,18 & 78,69 \\
\hline TOTAIS & 7,26 & \\
\hline \multicolumn{3}{|l|}{ RIDE DF } \\
\hline TOTAIS & 65,99 & \\
\hline MÉDIAS & 503,91 & 16,33 \\
\hline
\end{tabular}

Quadro 2 - Densidade Populacionais e Índices de Dispersão na RM Belém e RIDE DF Fonte: Elaboração própria a partir de dados do IBGE e Google Maps. 
Com base nos contextos apresentados até aqui, além do método utilizado por Castello et al $(2013)^{3}$ ao confrontar as nove regiões metropolitanas da década de 1970 e as atuais, foram estabelecidos critérios de corte, ou condições, a definirem se o município integra ou não aquela metrópole funcional. O Quadro 3 apresenta os critérios e limites de corte adotados:

\begin{tabular}{|c|l|}
\hline \multicolumn{2}{|c|}{ Limite de corte do critério } \\
\hline Critério 1 & Distância centro-município/RA superior a 100km; \\
\hline Critério 2 & Tempo de deslocamento menor que 100 minutos, equivalente a $100 \mathrm{~km}$ percorridos a 60km/h); \\
\hline Critério 3 & $\begin{array}{l}\text { Mais de 28\% de taxa de crescimento populacional na década 2000-2010, equivalente à média de crescimento das } \\
\text { duas aglomerações }\end{array}$ \\
\hline Critério 4 & $\begin{array}{l}\text { Densidade superior a 10\% da densidade média da aglomeração (50,3 hab/km² para Brasília e } 75,8 \mathrm{hab} / \mathrm{km}^{2} \text { para } \\
\text { Belém) }\end{array}$ \\
\hline Critério 5 & Índice de dispersão inferior à dispersão média da aglomeração (16,3 para Brasília e 3,65 para Belém) \\
\hline
\end{tabular}

Quadro 3 - Critérios e cortes adotados

Fonte: Elaboração própria.

Com base nos cálculos e métodos descritos, foi desenvolvido pelos autores, um caminho metodológico, por meio da pontuação, exclusivamente para o atendimento do artigo e suas análises. Tendo sido atribuída a nota -1 quando não se atendia o limite de corte do critério, foram definidos como parte das metrópoles funcionais os municípios e regiões administrativas que atendam a pelo menos três dos cinco critérios indicados (somatório de notas -2, -1 e 0) - ver Quadro 4. Finalmente foi realizada uma relativização dos resultados como indicado na sequência.

${ }^{3}$ Castello et al (2013) utiliza como critérios, derivados de Galvão et al. (1969): 1. População municipal de pelo menos 400 mil habitantes; 2. Densidade dos setores censitários urbanos de pelo menos 500 habitantes $/ \mathrm{km}^{2} ; 3$. Densidade municipal de pelo menos 60 habitantes $/ \mathrm{km}^{2}$; 4. Pelo menos $70 \%$ da sua população ocupada em atividades urbanas; 5 . Pelo menos $10 \%$ da população municipal total deslocando-se em viagens intermunicipais para trabalhar em qualquer outro município da área (considerando fluxos de entrada e de saída do município). 


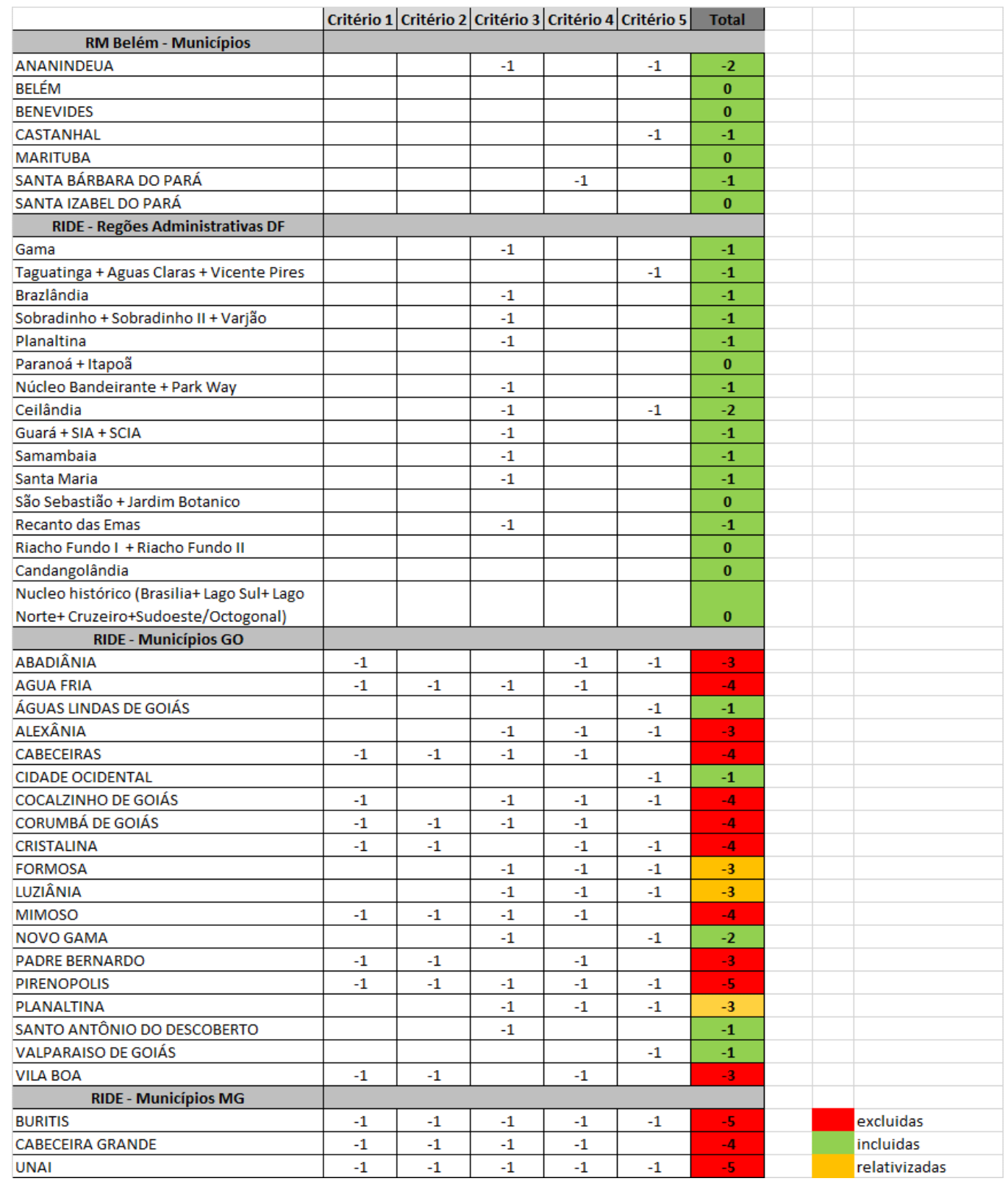

Quadro 4 - Resultados obtidos por os municípios e Regiões Administrativas das RM Belém e RIDE DF Fonte: Elaboração própria.

\section{RESULTADOS: METRÓPOLES COMPARADAS}

Os resultados indicam que a conformação de Belém, apresenta uniformidade, apesar de alguma discrepância quanto ao critério 4, densidade populacional, pois os valores Belém e Marituba se distanciam muito dos demais). Entretanto, a equidistância entre o centro e os municípios mais populosos, localizados a menos de $30 \mathrm{~km}$ da área central (Gráfico 1), faz o perímetro da RM Belém se aproximar da realidade metropolitana: um centro denso, cercado de uma periferia dispersa. 


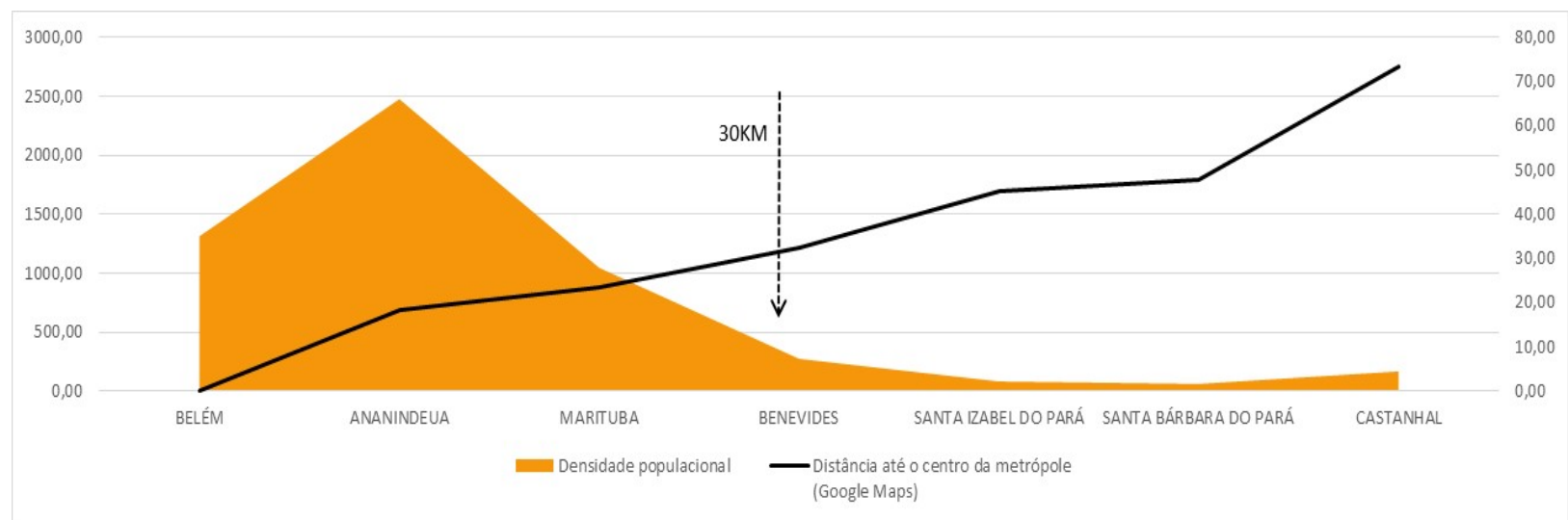

Gráfico 1 - Densidade populacional e distancias até o centro na RM Belém

Fonte: Elaboração própria a partir de dados do IBGE e Google Maps.

O mesmo não acontece com Brasília. Os dados indicam que a RIDE DF não reflete a metrópole, pois de todos os municípios e regiões administrativas, dezessete deles não atendem ao estabelecido. Os municípios mineiros, Buritis, Unaí e Cabeceira Grande apresentam-se inteiramente destacados da dinâmica metropolitana, estando muitos distantes do centro, possuindo baixas densidades e índices de incremento populacional típicos de cidades com crescimento estagnado.

Em Goiás, estão fora os municípios de Água Fria, Mimoso, Cabeceiras, Cocalzinho, Corumbá de Goiás e Cristalina. Também Padre Bernardo e Vila Boa, que além de muito distantes, apresentaram baixíssimas densidades (menos de $10 \mathrm{hab} / \mathrm{km}^{2}$ ), apesar de um expressivo crescimento populacional, mais associado ao dinamismo do agronegócio, presente na região central do Brasil, e menos às questões metropolitanas. Quanto às baixas dispersões de Vila Boa e Agua Fria, por exemplo, as baixas populações têm impacto no índice, mas outras variáveis não deixam dúvidas da desconexão com a realidade metropolitana. Por essas razões, os três municípios foram excluídos do perímetro funcional. Todas estão destacadas em meio ao campo, à exemplo das "cidades isoladas" de Indovina (2003).

Pirenópolis também está fora, pois não atende a nenhum dos cinco critérios, o que parece refletir sua condição de atrativo turístico, servindo a demandas eventuais por turismo e lazer, ou mesmo de segunda residência dos que partem tanto do Distrito Federal, como de Goiânia e de Anápolis (GO), mas não especificamente demandas metropolitanas típicas.

No eixo de desenvolvimento entre as cidades de Brasília e Goiânia, que possuem economias complementares de consumo e indústria (Exame, 2014), estão Alexânia e Abadiânia, ambas muito pouco densas e dispersas às duas metrópoles, não sendo possível definir a qual delas mais diretamente relacionadas. Será preciso aguardar a evolução desse fenômeno regional a impulsionar o desenvolvimento e em contrapartida a urbanização ao longo da rodovia BR 060.

A dúvida fica com Planaltina (GO), Luziânia e Formosa, pois as três não atendem a três dos cinco critérios, sendo necessária uma relativização dos resultados. No caso de Planaltina (GO), "das 38.310 pessoas com ocupação, observa-se que $43,9 \%$ (16.817) trabalham no próprio município e um alto percentual de 54,9\% (21.040 pessoas) trabalham no Distrito Federal" (Distrito Federal, 2015:27), fato que a caracteriza como cidade dormitório, quando expressiva parcela da população de um município exercer suas atividades profissionais fora só regressando ao final do dia. Daí não é possível excluí-la da metrópole funcional, mesmo que signifique uma exceção na metodologia. Fato semelhante ocorre em Luziânia, que apesar de relativa independência, $60,8 \%$ das pessoas trabalham no próprio município, quando se observa o distrito de Jardim Ingá, um loteamento periférico típico, denso e de baixa renda, verifica-se que 48,53\% dos moradores trabalham no Distrito Federal, segundo dados da PMAD (Distrito Federal, 2013).

Quanto a cidade de Formosa, apesar do relevante crescimento populacional, a manteremos fora do perímetro funcional, pois, assim como Cristalina, Padre Bernardo, Alexânia e Abadiânia, Formosa possui influência de fenômenos econômicos independentes, como relata o Diagnóstico do Plano Diretor De Desenvolvimento Integrado do município: "(...) a agropecuária vem induzindo o estabelecimento de um conjunto de atividades, como suporte urbano e industrial, a ela relacionados, especialmente o processamento de insumos agrícolas e minerais e o fornecimento de insumos industriais, cuja produção tende a se localizar junto às fontes de matérias-primas (...) O Setor Primário (agropecuária, extrativismo vegetal, etc.), cuja base de sustentação 
reside nas atividades agropecuárias e que se constitui em um dos polos econômicos do Município de Formosa e da sua região de influência imediata" (Formosa, 2016:49). Sua considerável extensão de área rural, refletida na baixa densidade populacional, alta dispersão e a distância do centro, levam a crer que elas se comportam mais com "território urbanizado" (Indovina, 2003) e menos como parte da metrópole funcional.

Com relação às Regiões Administrativas do Distrito Federal ${ }^{4}$, o que se observa é que a dispersão é muito mais evidente que aquela observada em Belém, pela quantidade de núcleos densos distribuídos muito mais além dos imites do núcleo histórico da capital brasileira, levando-se em consideração os mesmos $30 \mathrm{~km}$ de distância adotados para a RM Belém, como observado no Gráfico 2:

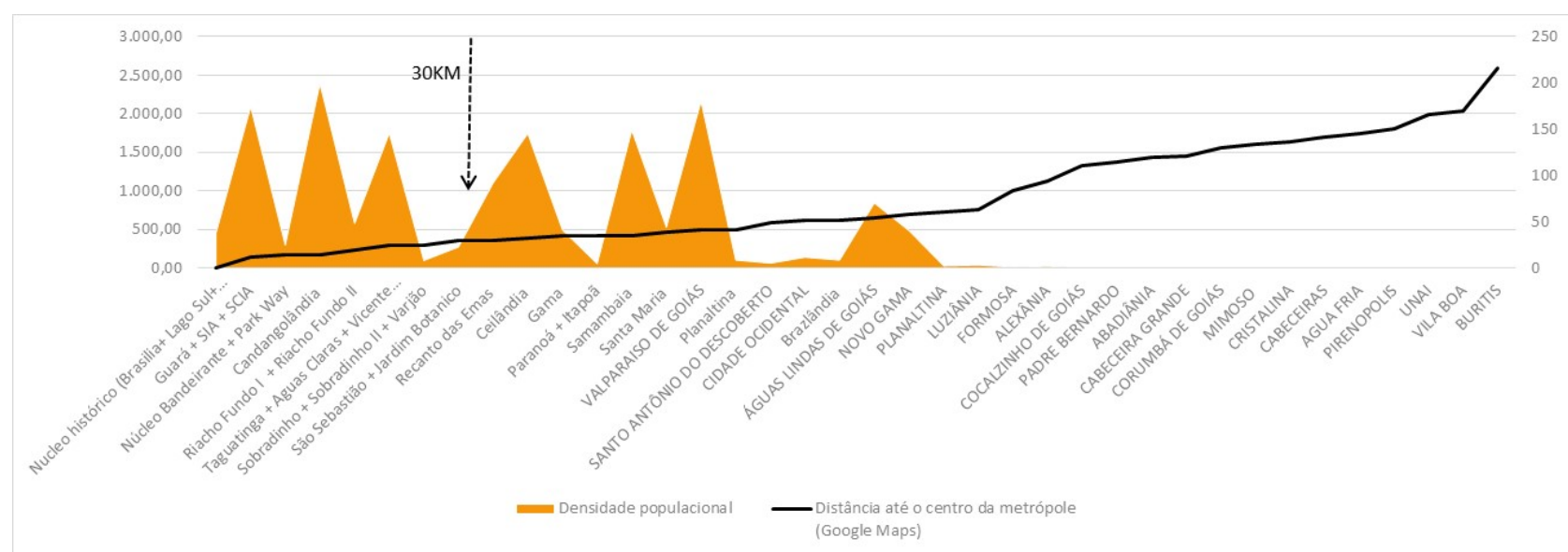

Gráfico 2 - Densidade populacional e distancias até o centro na RIDE DF Fonte: Elaboração própria a partir de dados do IBGE e Google Maps.

Cabe um destaque à Águas Lindas de Goiás, último dos picos do Gráfico 2, localizada para além dos 30km de referência. É outra cidade dormitório, de renda média mensal dos trabalhadores equivalente a 1,7 salários mínimos brasileiros (IBGE, 2015), dependente e distante do centro da Capital Federal, onde a renda média mensal do responsável pelo domicílio é de 11,5 salários mínimos (PMAD) ${ }^{5}$, dados que apontam a tal segregação espacial.

\section{CONSIDERAÇÕES FINAIS}

Num contexto global, Belém e Brasília são metrópoles em transformação, saindo de padrões tradicionais em busca de uma configuração diversificada, onde Belém é classificada como uma metrópole de atuação regional e Brasília como uma metrópole nacional (IBGE, 2008). Ambas estão conectadas às suas condições locais, crescem e se distinguem não só pelo tamanho das duas aglomerações, mas por seguirem modelos morfológicos distintos (Figura 6).

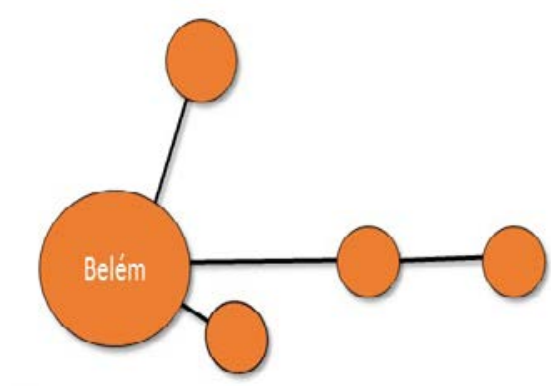

RM Belém

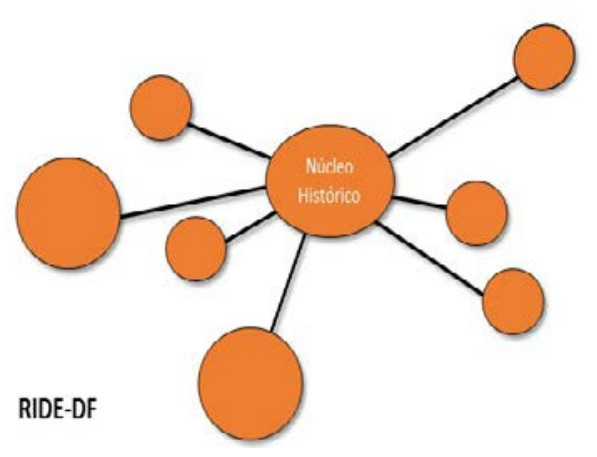

Figura 6 - Modelos morfológicos da RM Belém e RIDE DF Fonte: Elaboração própria.

No caso de Brasília foi observado um território disperso, polarizado economicamente pelo núcleo principal, o Plano Piloto de Brasília, sede do Governo Federal Brasileiro, indicando uma metrópole funcional, diverso da

\footnotetext{
${ }^{4}$ Era de se esperar que as RA não se destacassem do conjunto metropolitano funcional, o que de fato não ocorreu.

${ }^{5}$ Em abril de 2018 o salário mínimo brasileiro equivalia a 207 Euros.
} 
RIDE DF, relacionando menos municípios que os da composição legal: Águas Lindas de Goiás, Cidade Ocidental, Luziânia, Novo Gama, Planaltina, Santo Antônio do Descoberto e Valparaíso de Goiás, totalizando 19.897 km², que até podemos chamar Aglomerado Metropolitano de Brasília. A exceção de Formosa, pelas razões explicitadas anteriormente, seu desenho se aproxima do recorte utilizado pela Secretaria de Mobilidade do Distrito Federal, para a elaboração do Plano Diretor de Transportes Urbanos - PDTU.

Belém, ao contrário, apresenta adensamento adjacente ao centro e evidências de relações funcionais com os municípios que compõe sua Região Metropolitana instituída A comparação entre os dois territórios pode ser observado na Figura 7.

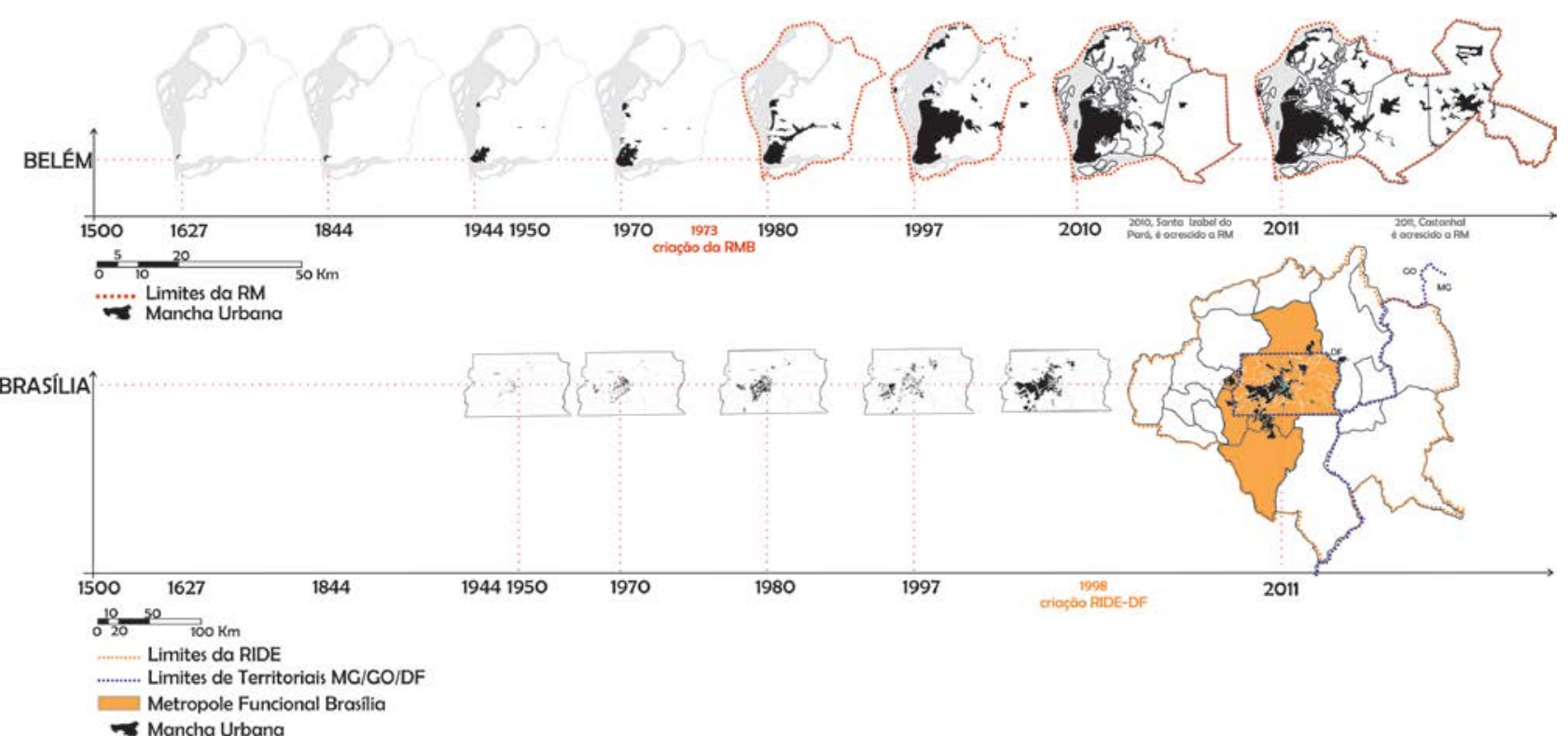

Figura 7: Dispersão de Brasília e Adensamento em Belém

Fonte: Fonte: Elaboração própria.

Neste contexto, é preciso destacar que, para além das medidas de superação dos problemas apontados, segregação socioespacial e transportes, o enfrentamento precisa ser feito a partir de dados e instâncias de gestão adequadas, com parceiros certos, mas principalmente considerando que as cidades crescem sob o paradigma da cidade difusa. Aquela baseada em nova lógica relação espaço-tempo (Secchi, 2003), com características de descontinuidade, em forte tendência de ampliação, além da existência de grandes áreas não construídas, a formar rupturas em seu tecido, muito embora, não menos urbanas (Panerai, 1999). Todavia, ainda persiste entre nós o modelo centro-periferia, pois como aponta Indovina (2003), o fenômeno difuso ainda se trata de uma tendência, com personagens peculiares, atuando em cada situação, e não um fenômeno consolidado.

\section{BIBLIOGRAFIA}

\section{Obras completas}

BARROS, A. P. G. (2014). Diz-me como andas que te direi onde estás: inserção do aspecto relacional na análise da mobilidade urbana para o pedestre. Brasília: Departamento de Engenharia Civil e Ambiental da Faculdade de Tecnologia da Universidade de Brasília.

BAUMAN, Z. (2001). Modernidade líquida. Tradução: Plínio Dentzien. Rio de Janeiro: Jorge Zahar.

BITENCOURT, R. B. (2005). A formação do espaço metropolitano da Capital do Brasil. Brasília: Faculdade de Arquitetura e Urbanismo da Universidade de Brasília.

BROWDER, J. O., GODFREY, B. J. (2006). Cidades da floresta: urbanização, desenvolvimento e globalização na Amazônia brasileira. Manaus: Universidade Federal do Amazonas.

CASTELLS, M. (2000). A Questão Urbana. Rio de Janeiro: Paz e Terra. 
DAVIS, M. (2009). Cidade de quartzo: escavando o futuro de Los Angeles. Tradução: Marco Rocha e Renato Aguiar. São Paulo: Boitempo.

DISTRITO FEDERAL. Secretaria de Estado de Gestão do Território e Habitação. SEGETH. (2009). Plano Diretor de Ordenamento Territorial do Distrito Federal - PDOT. Documento Técnico. Brasília.

DISTRITO FEDERAL. Secretaria de Estado de Mobilidade do Distrito Federal. (2009). Plano Diretor de Transporte Urbano e Mobilidade do Distrito Federal e Entorno. Relatório Técnico N. ${ }^{\circ} 5$ Diagnóstico da Situação Atual. Brasília.

DISTRITO FEDERAL. Secretaria de Estado de Mobilidade do Distrito Federal. (2009). Plano Diretor de Transporte Urbano e Mobilidade do Distrito Federal e Entorno - Relatório Técnico n. ${ }^{\circ} 7-P D T U / D F$. CENÁRIOS DE DESENVOLVIMENTO. Brasília.

GOROVITZ, M. (1985). Brasília, uma questão de escala. São Paulo: Projeto.

HOLANDA, F. d. (2011). Brasília: cidade moderna, cidade eterna. Brasília: Faculdade de Arquitetura e Urbanismo da Universidade de Brasília.

JACOBS, J. (2000). Morte e vida de grandes cidades. São Paulo: Martins Fontes.

KHOURI FILHO, A. y COSTA M. V. M. (2014). Anuário do DF 2014: uma ferramenta de fomento ao turismo e ao desenvolvimento do Distrito Federal. Brasília: Mark Comunicação.

KOOLHAAS, R. (2010). Três textos sobre as cidades. Barcelona: Gustavo Gili.

MEDEIROS, V. A. S. (2006). Urbis Brasiliae ou sobre cidades do Brasil: inserindo assentamentos urbanos do país em investigações configuracionais comparativas. Brasília: Faculdade de Arquitetura e Urbanismo da Universidade de Brasília.

PANERAI, P. (1999). Análise Urbana. Brasília, EdUnB.

REIS, N. G. (2006). Notas sobre urbanização dispersa e novas formas de tecido urbano. São Paulo: Via das Artes.

RIBEIRO, R. J. C. (2008). Índice composto de qualidade de vida urbana. Brasília: Faculdade de Arquitetura e Urbanismo da Universidade de Brasília.

SANTOS, M. (1990). Metrópole corporativa fragmentada: o caso da São Paulo. São Paulo: Nobel -Secretaria de Estado da Cultura.

SECCHI, B. (2009). A cidade do século vinte. São Paulo: Perspectiva.

SECCHI, B. (2015). La ciudad de los ricos y la ciudad de los pobres. Madrid: La Catarata.

SOJA, E. (2000). Posmetropolis: critical studies of cities in regions. Oxford, Massachusetts: Blackwell.

TRINDADE JR, S. C. (1997). Produção do espaço e uso do solo urbano em Belém. Belém: Núcleo de Altos Estudos Amazônicos da Universidade Federal do Pará.

--- (1998). A cidade dispersa: os novos espaços de assentamentos em Belém e a reestruturação metropolitana. São Paulo: Universidade de São Paulo.

\section{Capítulos de livros}

CASTELLO BRANCO, M. L. G., PEREIRA, R. H. M. y NADALIN, V. G. (2013). Rediscutindo a delimitação das regiões metropolitanas no brasil: um exercício a partir dos critérios da década de 1970. En FURTADO, Bernardo Alves; KRAUSE, Cleandro; FRANÇA, Karla Christina Batista de. Território metropolitano, políticas municipais: por soluções conjuntas de problemas urbanos no âmbito metropolitano. Brasília: Instituto de Pesquisa Econômica Aplicada - IPEA. 
COSTA, M. A. (2013). Quarenta anos de Regiões Metropolitanas No Brasil: Um Breve Balanço Exploratório. En 40 anos de RM no Brasil. Brasília: Instituto de Pesquisa Econômica Aplicada - IPEA.

DRUMMOND, M. V. D. y SILVEIRA; L. R. G. (2013). A gestão do território na RMBH, En 40 anos de RM no Brasil. IPEA, Instituto de Pesquisa Econômica Aplicada. Brasília: Instituto de Pesquisa Econômica Aplicada IPEA.

INDOVINA, Francesco (2004). La ciudad difusa. En. RAMOS, A. R. (Ed). Lo urbano en 20 autores contemporáneos. Barcelona: Ediciones UPC.

MARICATO, E. (2000). As ideias fora lugar e lugar fora das ideias: Planejamento urbano no Brasil. En ARANTES, O.; VAINER, Carlos B. MARICATO, Erminia. A cidade e o pensamento único: desmanchando consensos. Petropolis, RJ: Vozes.

PINHEIRO, A. C. L. et. al. (2013). Desafios da governança metropolitana na Região Metropolitana de Belém: alguns apontamentos. En Quarenta anos de Regiões Metropolitanas No Brasil: Um Breve Balanço Exploratório. In 40 anos de RM no Brasil. Brasília: Instituto de Pesquisa Econômica Aplicada - IPEA.

RODRIGUES, R. M. y PONTE, J. P. X. (2015). Organização Social do Território e Mobilidade Urbana, En Belém: transformações na ordem urbana. CARDOSO, Ana Cláudia Duarte; LIMA, José Júlio Ferreira (orgs); RIBEIRO, Luiz Cesar de Queiroz (coords.). Rio de Janeiro: Letra Capital: Observatório das Metrópoles.

SAMPAIO, C. S.; PAZ, F.; CORRÊA, G. y CASTRO, S. M. (2013). Arranjos institucionais de gestão Metropolitana: o caso da RIDE-DF. En 40 anos de RM no Brasil. Brasília: Instituto de Pesquisa Econômica Aplicada - IPEA.

\section{Artigos}

INDOVINA, F. (2003). La metropolizzazione del territorio. Nuove gerarchie territoriali. Economia e Società regionale - Oltre il Ponte, (Milano), n. 3/4, 1-25.

NOGALES, A. M. V. y GOMES, M. M. F. (2012). Transição demográfica: a experiência brasileira. Epidemiol. Serv. Saúde (Brasília), v.21, n.4, 539-548.

VELOSO, T. y TRINDADE JR; S. (2014). Dinâmicas sub-regionais e expressões metropolitanas na Amazônia brasileira: olhares em perspectiva. Novos Cadernos NAEA (Belém), v.17, n.1,177-202.

\section{Legislação}

BRASIL. (1988). Constituição da República Federativa do Brasil. Brasília: Senado Federal.

DISTRITO FEDERAL. (2011). Plano Diretor de Transporte Urbano e Mobilidade do Distrito Federal e Entorno. Lei $n^{\circ} 4.566$, de 04 de maio de 2011.

DISTRITO FEDERAL. (2009). Plano Diretor de Ordenamento Territorial do Distrito Federal - PDOT. Lei Complementar $N^{\circ} 803$, de 25 de abril de 2009.

\section{Fontes eletrônicas}

BORGES, R. C. N. (2006). Definição de transporte coletivo urbano - Nota Técnica. Brasília: Biblioteca Digital da Câmara dos Deputados. http://bd.camara.gov.br/bd/handle/bdcamara/1720 (Consulta: 28/02/2018) BRASIL. (1967)
http://www.planalto.gov.br/ccivil_03/constituicao/constituicao67.htm. (Consulta: 27/02/2018).

CAIXETA, E. A. (2014). Autonomia dos entes federados. Brasília: Conteúdo Jurídico. http://www.conteudojuridico.com.br/?artigos\&ver=2.46887\&seo=1 (Consulta: 12/02/2018). 
DISTRITO FEDERAL - Companhia de Planejamento do Distrito Federal - CODEPLAN (2013). Pesquisa Metropolitana por amostra de Domicílios - $\quad$ PMAD 2013. http://www.codeplan.df.gov.br/images/CODEPLAN/PDF/pesquisa_socioeconomica/PMAD/PMAD_Perfil_soc ioeconomico_dos_moradores_dos_municipios_da_AMB.pdf (Consulta: 28/02/2018).

DISTRITO FEDERAL - Companhia de Planejamento do Distrito Federal - CODEPLAN (2014). Pesquisa Distrital por amostra de Domicílios - PDAD Brasília/Plano Piloto 2014. http://www.codeplan.df.gov.br/wpcontent/uploads/2018/02/PDAD-Bras\%C3\%ADlia-Plano-Piloto.pdf (Consulta: 29/04/2018).

DISTRITO FEDERAL - Companhia de Planejamento do Distrito Federal - CODEPLAN (2015). Pesquisa Metropolitana por amostra de Domicílios - PMAD Planaltina 2015. https://www.agenciabrasilia.df.gov.br/images/agencia_brasilia/2016/Abril/pmad-planaltina-GO.pdf (Consulta: 27/02/2018).

EXAME. (2014). Conheça os principais corredores da riqueza no Brasil. https://exame.abril.com.br/revistaexame/corredores-da-riqueza/\#respond. (Consulta: 17/02/2018).

GALVÃO, M. V. et al. (1969). Áreas de pesquisa para determinação de áreas metropolitanas. Revista brasileira de geografia, Rio de Janeiro, ano 31, n. 4, p. 53-127, out.-dez. 1969. http://biblioteca.ibge.gov.br/visualizacao/periodicos/115/rbg_1969_v31_n4.pdf (Consulta: 12/02/2018).

GARSON, S.; RIBEIRO, L. C. Q. y RODRIGUES, J. M. (2010). Regiões Metropolitanas do Brasil. Observatório das Metrópoles. http://www.observatoriodasmetropoles.net/download/observatorio_RMs2010.pdf. (Consulta: 28/11/2017).

HOLANDA, F. (2001). Uma ponte para a urbanidade. Revista Brasileira de Estudos Urbanos e Regionais, [S.I.], n. 5, p. 59, nov. 2001. ISSN 2317-1529. http://rbeur.anpur.org.br/rbeur/article/view/65 (Consulta: 16/02/2018).

INSTITUTO BRASILEIRO DE GEOGRAFIA E ESTATÍSTICA - IBGE (2015). Águas Lindas de Goiás. Portal Cidades. https://cidades.ibge.gov.br/brasil/go/aguas-lindas-de-goias/panorama. (Consulta: 29/04/2018).

INSTITUTO BRASILEIRO DE GEOGRAFIA E ESTATíSTICA - IBGE (2010). Censo Demográfico 2010 Resultados Gerais da Amostra. http://www.ibge.gov.br/home/estatistica/populacao/censo2010/resultados_gerais_amostra/default_resultado S_gerais_amostra.shtm (Consulta: 27/02/2018)

INSTITUTO BRASILEIRO DE GEOGRAFIA E ESTATÍSTICA - IBGE. (2010). Aglomerados Subnormais, Informações territoriais. https://biblioteca.ibge.gov.br/pt/biblioteca-catalogo?view=detalhes\&id=7552 (Consulta 28/02/2018)

INSTITUTO BRASILEIRO DE GEOGRAFIA E ESTATÍSTICA - IBGE. (2008). Região de Influências de Cidades. Ministério do Planejamento, Orçamento e Gestão. http://www.mma.gov.br/estruturas/PZEE/_arquivos/regic_28.pdf (Consulta 28/02/2018)

PREFEITURA MUNICIPAL DE FORMOSA/GO. (2016). Plano Diretor de Desenvolvimento Integrado Município de Formosa - GO, Caderno 1 - Estatuto da Cidade e o processo de revisão do Plano Diretor Municipal de Formosa. https://formosa.go.gov.br/uploads/15f431b514e9f588a0774d71431e9075648dfbfd.pdf (Consulta:19/02/2018). 